\title{
Sobre El Príncipe y su virtud
}

"Dios no quiere hacerlo todo, para no quitarnos el libre albedrío y parte de la gloria que nos corresponde."

En este corto ensayo no pretendo agotar la riqueza del texto que fundo la modernidad política. Busco borronear unas pocas líneas sobre el concepto de virtud en El príncipe de Nicolás Maquiavelo, y desde allí esbozar su pertinencia sobre la práctica de la política en el presente. Considero que una ventana para acceder al pensamiento político de Maquiavelo es, precisamente, su noción de virtud. En ella, y en las diferentes acepciones que este término cobra a lo largo del libro, se encuentra el meollo y ambigüedad con que el autor florentino miró a la política y a la misión del político, el príncipe, en pleno renacimiento italiano. En parte dicha ambigüedad, y al mismo tiempo riqueza, se encuentra la forma como nosotros, aún hoy, miramos los actos políticos como una dimensión de la vida humana que paralelamente admiramos o repudiamos, adscribimos o la consideramos producto de la moral más detestable.

Para iniciar esta discusión reescribamos textualmente un segmento del capitulo con que Maquiavelo abrió su obra maestra, capítulo en donde sitúa el papel de la virtud y la fortuna en la adquisición de las distintas clases de principados. Maquiavelo dice:

Todas las formas de gobierno y todos los territorios en los que han sido dominados los hombres han ejercido su autoridad por medio de una república o de un principado. Los principados pueden ser: hereditarios o adquiridos. Los adquiridos son, ya de nueva formación en todo, caso de Milán para Francisco Sforza, ya a manera de miembros añadidos al antiguo Estado del príncipe que se anexiona el nuevo principado, como lo ha sido el reino de Nápoles con respecto al rey de España. Los dominios adquiridos de esta manera se ven obligados a vivir bajo el poder de un príncipe, 0 bien pueden vivir libres; el príncipe que los adquirió lo hizo por medio de armas ajenas, o con sus mismas armas, y fueron la fortuna o la virtú las que lo permitieron. ${ }^{2}$

El libro despacha en unas cuantas frases del capítulo 2 lo pertinente a los principados hereditarios y se concentra, en los veititres capítulos restantes, en los dominios nuevos y adquiridos. De entre los segundos, las discusión principal se centra en aquellos obtenidos no por armas ajenas sino con sus mismas armas, y allí Maquiavelo nombra los dos términos en que enfocaremos nuestro análisis: fortuna y virtud.

Según la concepción medieval, fortuna es suerte, generalmente negativa. La fortuna ayuda a la virtud, sin fortuna la virtud puede fracasar. ${ }^{3}$ En El príncipe, la fortuna es responsable de la mitad de nuestras acciones, pudiendo la otra mitad ser gobernada por los hombres. La fortuna domina el destino humano cuando no encuentra virtud que la resista. Las virtudes se oponen y resisten a la suerte. Por ello, el príncipe que se apoya sólo en la suerte, se entrega totalmente a ella, y se desmorona cuando ésta cambia. Debe, en ese sentido, armonizar su accionar con las circunstancias o las condiciones de la fortuna en que le toca vivir... es feliz aquel que armoniza su modo de proceder con la calidad de las circunstancias, y de la misma manera que es infeliz aquel cuyo proceder está en discordancia con los tiempos. ${ }^{4}$

En la perspectiva de Maquiavelo, la fortuna, además de referirse a la suerte, es parte de las circunstancias, negativas o positivas, en que se desenvuelven las acciones del príncipe. La fortuna es el contexto en el que ocurre su intervención política; es el campo exterior a su voluntad; el campo de lo no controlado y contingente a su acción y a su habilidad. El príncipe debe incidir sobre las circunstancias. No puede limitarse a guardar una posición pasiva frente a ellas sino dominarlas con ímpetu y audacia. Maquiavelo feminiza a la fortuna, masculiniza a la virtud y a la acción.

mejor ser impetuoso que circunspecto, porque la fortuna es mujer: y es necesario, cuando queremos tenerla sumisa, zurrarla y zaherirla. Se ve, en efecto, que se deja vencer más por éstos, que por los que proceden fríamente. Por otra parte siempre, como mujer, es amiga de los jóvenes, porque son menos circunspectos, más iracundos y le mandan con más audacia.

La feminización de la fortuna es muy expresiva respecto a la tensión que existe entre fortuna y virtud en el pensamiento de Maquiavelo. El sometimiento de la fortuna, de la suerte y de las circunstancias debe valerse del ímpetu y la audacia del príncipe, aquí consideradas virtudes suyas. Necesita hacer uso de la fuerza de su voluntad; zurrar, herir, zaherir a la suerte para mandar sobre ella y volverla sumisa.

Si la noción maquiavélica de fortuna tiene, al menos, un doble significado, el concepto de virtud es mucho más complejo y puede dar lugar a múltiples interpretaciones. De acuerdo a George Bull, uno de los traductores de El príncipe al inglés, el significado de las palabras que utiliza Maquiavelo no deben ser interpretadas en su sentido moderno. En el caso de la palabra virtud, Maquiavelo la utilizó de manera libre y sin mayor rigurosidad, casi siempre como antítesis de la fortuna, para significar algunas veces voluntad de poder, otras eficiencia, otras virtudes. ${ }^{6}$ Guido Castillo, otro traductor de Maquiavelo, sostiene que el autor florentino entiende la palabra virtud como fuerza interna y activa del hombre, la cual, incluso, podía vencer a la suerte. ${ }^{7}$ Esta fuerza interna, sin embargo, es racional. Se relaciona con la capacidad de comprender en términos racionales el entorno - las circunstancias para canalizar la voluntad de quien quiere adquirir un principado. En ese sentido, virtud podría 
entenderse como fuerza interna más racionalidad, más talento. Complementariamente, Leo Strauss y Joseph Cropsey entienden virtud como una cualidad distinta a la bondad. La bondad es característica de la población ocupada de asuntos pacíficos, mientras que la virtud es requerida por gobernantes y soldados. Aún más, el término bondad está relacionado con obediencia, y la obediencia debe ser una cualidad del pueblo y no de quien tiene vocación de poder. Quien gobierna, es decir quien manda y no obedece, se encuentra exento de atar su comportamiento a la bondad. Para el gobemante y el soldado rige la virtud, cualidad que no excluye la utilización de medios despojados de todo escrúpulo moral. El uso, de acuerdo a las circunstancias, de actos morales y de vicios se encuentra en el rango de posibilidades para quien manda.

El capitulo 15 de El príncipe nos ofrece una muestra del maquiavelismo clásico, así entendido como la concepción de que el fin justifica cualquier medio, lícito o ilícito, y como una advertencia sobre el costo que tiene para el gobernante el mantenerse en el reino imaginario de la bondad. Allí el autor aclara que su misión es seguir la verdad real de la materia y no los desvaríos de la imaginación concerniente a ella y, a renglón seguido, sostiene:

Hay tanta distancia de cómo se vive a cómo se debería vivir, que el que deja el estudio de lo que se hace para estudiar lo que se debería hacer aprende más bien lo que debe obrar su ruina que lo que debe preservarle de ella: porque un hombre que en todas las cosas quiera hacer profesión de bueno, entre tantos que no lo son, no puede llegar más que al desastre... Y yo sé que todos confesarán que sería cosa muy loable que en un príncipe se encontraran todas las cualidades mencionadas, las que son tenidas por buenas: pero, como no se puede tenerlas todas, ni observarlas a la perfección, porque la condición humana no lo consiente, es necesario que el príncipe sea tan prudente que sepa evitar la infamia de los vicios que le harían perder el Estado, y preservarse, si le es posible, de los que no se harían perder; pero si no puede, estará obligado a menos reserva abandonándose a ellos. Sin embargo, no tema incurrir en la infamia de aquellos vicios sin los cuales difícilmente pueda salvar al Estado; porque, si se pesa bien todo, se encontrará que algunas cosas que parecen virtudes, si las observa, serán su ruina, y que otras que parecen vicios, siguiéndolas, le proporcionarán su seguridad y su bienestar.?

Luego de revisar este fragmento, sería muy fácil quedarnos en el simple repudio al maquiavelismo, típico en la mayoría de interpretaciones de El príncipe. Propongo, en cambio, explorar las premisas de su realismo y dejar, al menos por un momento, los descarnados y crudos ejemplos con los que intentó graficar sus consejos a Lorenzo de Médicis. Para ello, quizá, debemos partir de un masoquista ejercicio anti-estético consistente en abstraernos de su fascinante forma, de hecho El príncipe es uno de los textos fundacionales de la lengua italiana, y referimos más bien a las ideas que subyacen a aquellas vívidas y alucinantes prescripciones. Advierto mi inseguridad de que lo propuesto sea riguroso y posible, pues al leer El príncipe no podemos olvidar jamás que se trata de un libro de recomendaciones políticas y que la belleza y expresividad del texto se hallan subordinadan a su propósito prescriptivo.
Pero retornemos al párrafo transcrito del capítulo XV. La premisa sobre la que descansa la prosa de Maquiavelo es que el gobernante no puede actuar en el mundo imaginario del deber ser. Su campo de acción no se sitúa en el ámbito de las ideas o de sus sentimientos y afecciones, sino en lo que la condición humana le consienta. El gobernante actúa y debe responder a esa condición, la misma que le exige discernir entre lo que le permitiría conservar o perder su Estado. El aspecto central es ubicar las condiciones reales de la intervención política, renunciando a lo deseable para alcanzar el orden político posible. Maquiavelo propone un descenso de la imaginación a la realidad; del deber ser a la existencia. El maquiavelismo no consiste en hacer el mal por el mal, sino en distinguir lo posible de lo deseable y desde allí intervenir en la realidad. Esta distinción, que posiblemente hoy nos parece obvia, es sin lugar a dudas uno de los mayores aportes de Maquiavelo al pensamiento y a la práctica políticos modernos. Y ello, porque no hay posibilidad alguna de una intervención sobre la realidad, sustento de la promesa de la modernidad, si es que el actor no pasa por el proceso racional de descender a la condición en la que pretende intervenir. Este descenso requisito de toda posibilidad de actuar, es condición indispensable de toda agencia.

Esta dimensión del maquivelismo es tan vigente hoy como lo fue en el siglo XV. Esta vigencia rebasa al cinismo presente en las lecturas simplistas de Maquiavelo que pretenden encontrar entre sus líneas justificación para cualquier acción. Reducir el maquiavelismo a la sentencia de que el fin justifica cualquier medio es perder de vista el salto esencial que Maquiavelo dio para el pensamiento político moderno al llamar la atención sobre la distancia entre cómo se vive y cómo se debería vivir. Uno, incluso, podría sostener que mantenerse en el reino imaginario del deber ser implica auto despojarse de la capacidad de actuar; renunciar a la posibilidad moderna de la agencia. No hay intervención posible sin realismo. Incluso, los principios más elevados requieren, en la pretensión de ser actualizados, de la distinción a la que nos convoca Maquiavelo. Sencillamente no hubiera sido posible concebir la agencia política en el mundo moderno sin $\mathrm{El}$ príncipe. Ello es mucho más importante y trascendente que el cinismo o perversidades de sus aprendices más vulgares.

Pero aún para la maldad extrema, para las acciones que Maquiavelo nombra como actos de rigor, las líneas de $\mathrm{El}$ príncipe ofrecen una argumentación política a favor de la consecución de un orden, basado en la predictibilidad y la confianza, frente al caos que produce una violencia no dosificada ni sistemática. Al final del capítulo VIII, Maquiavelo escribe:

Al conquistar un Estado, debe el ocupador pensar en todos los actos de rigor que le es necesario hacer, y hacerlos todos de una sola vez, para no tener que renovarlos todos los días, y poder, no renovándolos, tranquilizar a los hombres y ganárselos haciéndoles bien. El que actúa de otro modo por timidez, o por malos consejos, se ve obligado a tener siempre la cuchilla en la mano; y no puede contar nunca con sus súbditos, al no poder éstos, a causa de sus recientes y continuas ofensas fiarse de él. Los actos de rigor se deben hacer todos juntos, a fin de que, habiendo menos distancia entre ellos, ofendan menos; en cambio los beneficios se deben hacer poco a poco; a fin de que se saboreen mejor. Un prínci- 
pe debe ante todo conducirse con sus súbditos de manera que ninguna contingencia buena o mala le haga variar; porque si sobrevinieran tiempos adversos y difíciles, no le quedaría ya lugar para remediar el mal; y el bien que hace entonces no le aprovecha pues lo miran como forzoso y no se lo agradecen..$^{10}$

Efectivamente, la virtud incorpora la idea de utilizar la violencia en función de generar confianza entre príncipe y súbditos. En tales circunstancias, los actos de rigor favorecen a los súbditos, generan orden. El castigo, cuando es propicio, sólo afecta al particular que transgredió la autoridad. Lo contrario, la demasiada clemencia genera desórdenes, asesinatos y rapiñas que ofenden a la universalidad de los ciudadanos." Los actos de rigor del príncipe, administrados con prudencia y humanidad, hacen bien a aquella universalidad, producen un orden conveniente para el conjunto. Para lograrlo, se requiere que el príncipe no varíe; que sus subordinados se fíen de sus acciones y él pueda, a su vez, no tener que portar un cuchillo para estar tranquilo. Para el príncipe, por ello, es mejor ser temido antes que amado. Los hombres, en general, son ingratos, volubles, simuladores y disimulados... tienen menos consideración en ofender a uno que se haga amar que a uno que se haga temer; pues el amor se retiene por el vínculo de gratitud, el cual, debido a la perversidad de los hombres, es roto en toda ocasión de propia utilidad; pero el temor se mantiene con un miedo al castigo que no abandona a los hombres nunca. ${ }^{12}$ Nuevamente la condición humana dicta el modo de proceder del príncipe. Él no creó dicha condición sino que debe adecuarse a ella, sin tener miedo ser cruel. Ello no solo por él mismo sino por el orden que conviene a la universalidad. De lo contrario primarán la rapiña, los asesinatos, las ofensas a la universalidad.

Elemento fundamental de la virtud es la prudencia, a saber, la capacidad de prever en el tiempo. Los romanos, según Maquiavelo, hicieron, en estos casos, aquello que todos los príncipes prudentes deben hacer: los cuales príncipes no solamente han de tener cuidado con los desórdenes que puedan desencadenarse en el momento presente, sino que han de prever los futuros y evitarlos con destreza: porque teniendo precaución de que no ocurra ningún contratiempo en el presente, se prevé todo contratiempo venidero y se evita. ${ }^{13}$ En Maquiavelo la prudencia se relaciona íntimamente con la astucia. ${ }^{14}$ La prudencia, en ese sentido, constituye la virtud del príncipe que le permite proyectar su acción en el tiempo. Así, la agencia política no es momentánea ni puntual; no es sólo contemporánea. La prudencia llama al príncipe a pensar sus acciones incorporando un sentido de anticipación a los acontecimientos futuros. Ello le exige adoptar una actitud estratégica frente a sí mismo y a sus aliados y enemigos. Esta actitud pasa por imaginar un modo por el cual sus ciudadanos, siempre y en cualquier circunstancia, tengan necesidad del Estado y de él: así siempre le serán fieles. ${ }^{15}$ Asegurar la fidelidad de sus súbditos para el futuro es una de las exigencias del príncipe prudente. El gobernante requiere ser percibido como necesario por su pueblo hoy y mañana.

El príncipe no descansa si es que el presente le es favorable. Su mente debe estar concentrada en el presente y en el futuro. La prudencia le demanda a no gozar jamás de los beneficios del tiempo. Debe tomar con anticipación las decisiones que requiere el mañana sin ceder a la comodidad que le puedan ofrecer las circunstancias presentes. Maquiavelo así lo advierte: Pero los romanos, viendo con anterioridad los inconvenientes, los remediaron siempre y no permitieron que siguieran su curso por temor a la guerra, porque sabían que la guerra no se evita, y si se la difiere es en provecho ajeno. ${ }^{16} \mathrm{Su}$ acción presente no sólo incide sobre su actualidad sino que busca modelar el futuro, acercarlo a su interés y favor.

Pero la prudencia presenta un rasgo adicional de complejidad. Toda decisión tomada por el príncipe prudente se mueve siempre en el campo de la incertidumbre. La prudencia del gobernante consiste también en conocer la calidad de inconvenientes que se le presentarán en adelante y optar por el menos malo. No hay decisión perfecta. Desde el presente, es imposible prefigurar completamente el porvenir y toda decisión prudente se basa en escoger entre opciones desconocidas. ${ }^{17}$ Por ello, en muchos casos, la imitación es buena consejera. La imitación también es parte de la prudencia. Si imitándolos, el príncipe no logra igualar a los varones insignes del pasado, al menos puede acercarse a ellos. ${ }^{18}$

Otra manera en que Maquiavelo menciona a la virtud es como grande industria o habilidad. ${ }^{19} \mathrm{Al}$ mencionar la intervención política del príncipe en los principados adquiridos, pone énfasis en su dificultad, para lo cual explícitamente menciona que será necesario mucha suerte y habilidad para retenerlas. La agencia política es una labor compleja y laboriosa en la que el príncipe debe hacer lo que debe hacer sin escatimar esfuerzo. Según Maquiavelo, así actuaron los romanos en las regiones que conquistaron. Ellos respetaron muy bien las reglas de lo que debían hacer: asentaron colonias en los territorios conquistados, mantuvieron controlados a los poderosos, los debilitaron, se opusieron a la entrada de extranjeros con poder. ${ }^{20}$ Además de ello, los romanos se cuidaron de no ofender a los conquistados, se hicieron temer en los casos necesarios, actuaron con tenacidad e inteligencia.

La virtud maquiavélica contiene una altísima dosis de rigurosidad en la acción política, rigurosidad que cuida hasta el último detalle para conseguir su objetivo. El príncipe no puede descuidarse y debe actuar con aguda meticulosidad Así, la virtud le ayudará a conseguir, cuidar y mantener sus dominios. ${ }^{21}$ Maquiavelo se refiere a reglas racionales que hay que cumplir meticulosamente; que deben ser observadas para evitar el fracaso. Se trata de un sistema sin pasión creado industriosamente, laboriosamente, rigurosamente. Si su poder disminuye, será por sus propios errores y negligencia. A nadie más que a él se puede responsabilizar de que surjan poderes que lo limiten o lo venzan. Quien se acusa de que otro se vuelva poderoso -advierte Maquiavelo- obra su propia ruina; porque con su propia industria y con su fuerza ha causado aquel poderío, y uno y otro de estos dos medios resultan sospechosos a aquel que se ha vuelto poderoso. ${ }^{22}$

La virtud es casi sinónimo de valor. Solo su valor puede defender al príncipe de la adversidad. Allí reside su mayor fortaleza y su principal arma; arma que no depende de nadie más sino de él y de sus propias tropas. El príncipe no puede depender de las fuerzas de otros, de tropas mercenarias a las que tenga que pagar un salario. Sus defensas deben recaer en sí mismo. ${ }^{23}$ Esta autonomía del príncipe hace referencia al hecho de que la virtud es una característica propia, interna. Si la fortuna es el ámbito de lo externo al 
príncipe, la virtud hace parte de sí mismo, se refiere a sus propias decisiones y energía interna; a su fuerza interior y a su voluntad. Ello explica el por qué, al hablar del amor o temor que el político debe inspirar en el pueblo, Maquiavelo aclara que éste debe buscar el segundo y no el primero. El amor del pueblo es externo al príncipe, de ahí que no deba buscarlo; el temor del pueblo, en cambio, puede ser provocado por el gobernante y sólo depende de él.

Prudencia, laboriosidad y rigurosidad; capacidad para distinguir entre lo deseable y posible; valor para escoger lo segundo y proceder con los actos de rigor que sean necesarios; criterio para no dejar pasar la ocasión propicia, para no dejarse atemorizar por la adversidad; decisión de fundar su poder en armas propias y no prestadas, destreza para hacerse percibir como necesario en las situaciones buenas y en las malas; todas estas virtudes pueden ayudar al príncipe a vencer a la fortuna y recobrar la mitad de su destino; aquella porción que Dios dejó a los hombres para no arrebatarles el libre albedrío y la gloria que les corresponde. Cuando el príncipe logra apropiarse de la mitad de sus acciones, entonces es alabado y tiene al pueblo de su lado. Su deseo de adquirir es natural y ordinario. El problema es lograrlo sin fracasar. De lo contrario caerá en el error o el vituperio. Cuando tiene éxito el pueblo reconocerá sus fundamentos, los seguirá y los considerará buenos. Para ello, sólo un requisito es indispensable: no hacerse odiar por el pueblo. El príncipe debe hacerse tener como cruel y riguroso, debe hacerse temer en vez de amar; pero fundamentalmente no puede permitirse el hacerse odiar. Allí radica la base de su legitimidad y de toda la legitimidad política, pudiéramos agregar. Allí radica su fuerza, la misma que no depende de nada externo a él sino que le es propia. El amor, el cariño no dependen del ser amado o querido; están del lado de quien ama o quiere. Aquel o aquellos tienen la atribución de dejar de amar o querer y, cuando eso ocurre, entonces cambia completamente la situación del objeto del amor.

La visión de Maquiavelo sobre la relación de afecto entre el príncipe y su pueblo es contraria al sentido común del populismo y su retórica. El maquiavelismo es racional y antipopulista. La política de El príncipe es rigurosa, metódica y autónoma; su autoridad se basa en su fuerza interna. El caudillo populista, en cambio, halaga al pueblo, lo engríe sobre la base de que éste es el sustento principal de su po- der, lo seduce para sentirse seguido y amado por él. El populismo asentado sobre estructuras clientelares de intercambio de favores se sustenta sobre las mismas premisas. De ahí que la autoridad política que emana del populismo no depende del líder sino del pueblo. El amor y favor popular deben ser conseguidos con adulación y favores que constantemente debilitan a la autoridad. Nada más opuesto a lo prescrito por Maquiavelo. Para él, ninguna fuente de legitimidad externa puede ser característica de una sólida y genuina autoridad política. Toda la autoridad política debe provenir de fuentes propias, de las mismas armas; de la virtud como energía interna. El modo de adquirir un principado es un sistema racional; es una voluntad guiada por una racionalidad que debe persistir con prudencia y lograse con valor y oportunidad. Allí, el príncipe no debe ofender al pueblo y, sobre todo, debe buscar no ser odiado por aquel. Ello basta. Para Maquiavelo, el príncipe sí puede satisfacer al pueblo, incluso en mayor medida que a los grandes... porque el fin del pueblo es más honrado que el de los grandes, queriendo éstos oprimir, y aquel no ser oprimido. ${ }^{24} \mathrm{El}$ pueblo es numeroso y llevará a cabo lo indispensable para salvarse. El príncipe no podrá estar nunca seguro si tiene al pueblo como enemigo. Con los grandes el asunto es distinto. Los magnates cambian, son pocos y pueden desaparecer o reaparecer. El príncipe, por el contrario, vivirá siempre con el mismo pueblo. ${ }^{25}$

Dominar es un ejercicio frío, sistemático; producto de una voluntad interna que intenta modelar a la fortuna. Nada más. Pareciera un ejercicio simple, cargado de lógica y pulcritud; pero es al mismo tiempo una vocación atravesada por el valor y el ímpetu de quien, a diferencia de todos los demás, tiene una apetencia superior que lo lleva a hacer todo lo que esté a su mano para dominar y poseer. La virtud convierte al príncipe no en un hombre moral sino en una máquina que produce y reproduce autoridad. Esta suerte de deshumanización es ciertamente paradójica si consideramos que es la virtud lo que le permite apropiarse de una parte de las circunstancias que marcan su destino, arrebatándoselas a Dios y a la fortuna. Sin embargo, ese es el camino de todo aquel que busque mandar y no obedecer; y quiere mandar bien, en función de lo que es conveniente para la universalidad de los ciudadanos, sin caer en el error o el vituperio. 1986, pág. 7. Todas las citas referidas al texto se referirán a esta edición y traducción. En adelante se citará como El príncipe.

2. El Príncipe, pág. 7.

3. El Príncipe, pág. 111.

4. El Príncipe, pág. 103-104

5. El Príncipe, pág. 106.

6. George Bull, "Introducción" The Prince. Londres: Penguin Classics, 1961, pág. 25.

7. El príncipe, pág. 111.

8. Leo Strauss, Niccolo Machiavelli, en Leo Strauss y Joseph Cropsey (edt.), History of political philosophy. Chicago. Chicago University Press, 1987, pág. 301.

9. El Príncipe, pág. 64-65.

10. El Príncipe, pág. 39-40.

11. El Príncipe, pág. 69.

12. El Príncipe, pág. 69-70.

13. El Príncipe, pág. 14. 
Notas 14. El Príncipe, pág. 114.

15. El Príncipe, pág. 45.

16. El Príncipe, pág. 14-15.

17. El Príncipe, pág. 95.

18. El Príncipe, pág. 24.

19. El Príncipe, pág. 11.

20. El Príncipe, pág. 13.

21. El Príncipe, pág. 8.

22. El Príncipe, pág. 18.

23. El Príncipe, pág. 24, 58, 60, 102.

24. El Príncipe, pág. 42.

25. El Príncipe, pág. $42,43$. 